\title{
POTENCIAÇÃO ALELOPÁTICA DE EXTRATOS VEGETAIS NA GERMINAÇÃO E NO CRESCIMENTO INICIAL DE PICÃO-PRETO E ALFACE
}

\author{
Allelopathy of plant extracts on germination and initial growth of beggartick (Bidens pilosa $\mathbf{L}$.) \\ and lettuce (Lactuca sativa L.)
}

\author{
Magda Cristiani Ferreira1, José Roberto Pinto de Souza², Terezinha de Jesus Faria ${ }^{3}$
}

\begin{abstract}
RESUMO
O picão-preto (Bidens pilosa L.) é uma planta daninha muito agressiva, que está presente em quase todo Brasil. O principal método de controle é o químico, porém apresenta elevado impacto ambiental, risco de intoxicação humana e possibilidade de causar fitotoxicidade as culturas. O objetivo do trabalho foi avaliar o efeito alelopático de extratos etanólicos de Eucalyptus citriodora Hook. e Pinus elliottii L. na germinação e no crescimento inicial de picão-preto e alface (Lactuca sativa L.). Foram testadas quatro concentrações de cada extrato $(0,25 ; 0,50 ; 1,0$ e $2,0 \%)$ além do controle $(0,0 \%)$ água destilada com Tween 20 a $0,08 \%$. O delineamento experimental foi o inteiramente casualizado, com quatro repetições em condições de laboratório. O extrato de $P$. elliottii não causou efeito alelopático sobre o picão-preto e o alface. O extrato de $E$. citriodora reduziu significativamente o índice de velocidade de germinação (IVG) do picão-preto em todas as concentrações testadas quando comparadas com o controle $(0,0 \%)$, porém para a alface o IVG foi significativo apenas na concentração de 2,0\%. Para o comprimento da raiz não foi possível observar diferença significativa entre os tratamentos para os dois extratos testados tanto para o alface como para o picão preto.
\end{abstract}

Termos para indexação: Eucalyptus citriodora, Pinus elliottii, Bidens pilosa, Lactuca sativa.

\begin{abstract}
Bidens pilosa $\mathrm{L}$. is an aggressive weed found all over Brazil. The main control method for this species is chemical treatment however, causes strong environmental impact, and it has great human contamination risks, and may cause phytotoxity to crops. The objective of this study was to evaluate the effect of ethanolic extracts of Eucalyptus citriodora Hook. and Pinus elliottii L. on seed germination and initial growth of B. pilosa and lettuce (Lactuca sativa L.). Five concentrations of each extract $(0.0 ; 0.25 ; 0.50 ; 1.0$; $2.0 \%$ ) were tested in laboratory conditions using a randomized complete block design with four replicates. $P$. elliottii extract had no effect on $B$. pilos $a$ and lettuce. However, E. citriodora extract, significantly reduced germination index (GI) of $B$. pilosa, in all tested concentrations, when compared with the control composed by distilled water. Lettuce GI was affected only by $2,0 \%$ concentration of ethanolic extract. Extracts of both $P$. elliottii and E. citriodora had no significant effect on the root length parameter of both $B$. pilosa and lettuce.
\end{abstract}

Index terms: Eucalyptus citriodora, Pinus elliottii, Bidens pilosa, Lactuca sativa.

(Recebido em 10 de março de 2006 e aprovado em 12 de dezembro de 2006)

\section{INTRODUÇÃO}

A presença de plantas daninhas na lavoura é um dos principais problemas enfrentados pelos agricultores, elevando o custo de produção. Nos locais onde se pratica agricultura intensivamente, ocorrem modificações na população destas plantas, passando a predominar as espécies que melhor se adaptam àquelas condições (FAVERO et al., 2001). A interferência dessas plantas nas culturas de interesse comercial se dá devido à competição por água, luz, $\mathrm{CO}_{2}$ e nutrientes e também pelo efeito alelopático, provocando a redução qualitativa e quantitativa na produção (BIANCHI, 1995).

A espécie Bidens pilosa, popularmente conhecida como picão-preto, é uma planta herbácea originária da
América Tropical com maior incidência na América do Sul. No Brasil, está presente em quase todo território, porém, concentra-se nas áreas agrícolas das regiões Sul e CentroOeste, na qual constitui em uma das mais importantes plantas daninhas de culturas anuais e perenes, sendo apontada como tal em mais de 40 países. É uma invasora bastante agressiva, que além de competir com a cultura pode servir de hospedeiro de pragas e doenças, podendo provocar perdas significativas de produtividade em culturas agrícolas. Sua reprodução ocorre via sementes, possui crescimento rápido e pode ser encontrada durante todo o ano, mas as maiores infestações ocorrem durante as estações mais quentes, ou seja, primavera e verão (KISSMANN, 1997).

\footnotetext{
'Engenheira Agrônoma, Doutoranda - Centro de Ciências Agrárias/CCA - Universidade Estadual de Londrina/UEL - Cx. P. 6001 - 86051-990 - Londrina, PR cfmagda@yahoo.com.br

${ }^{2}$ Engenheiro Agrônomo, Professor, Doutor - Centro de Ciências Agrárias/CCA - Universidade Estadual de Londrina/UEL - Cx. P. 6001 - $86051-990$ Londrina, PR - jose@uel.br

${ }^{3}$ Farmacêutica Bioquímica, Professora, Doutora - Centro de Ciências Exatas/CCE - Universidade Estadual de Londrina/UEL - Cx. P. 6001 - 86051-990 Londrina, PR - tjfaria@uel.br
} 
O método de controle mais utilizado para o picãopreto é o químico, pois se a eliminação for mecânica podese esperar uma nova geração em poucos dias, visto que o revolvimento do solo traz à superfície, sementes com condições de germinar. No entanto, dentro da espécie $B$. pilosa ocorrem biótipos, alguns dos quais resistentes a determinados herbicidas (KISSMANN, 1997). Além disso, o controle químico apresenta elevado impacto ambiental, risco de intoxicação humana e possibilidade de causar fitotoxicidade às culturas. Esses fatores justificam a realização de estudos para identificar práticas de manejo que reduzem a utilização de produtos químicos, tais como práticas culturais fundamentadas na alelopatia (BALBINOT-JUNIOR, 2004).

Alelopatia é definida por Rice (1984) como sendo qualquer efeito direto ou indireto, danoso ou benéfico, que uma planta (incluindo microrganismos) exerce sobre a outra pela produção de compostos químicos liberados no ambiente. A maioria desses compostos provém do metabolismo secundário e estão simultaneamente relacionados a mecanismos de defesa das plantas contra ataques de microrganismos e insetos (MEDEIROS, 1990).

A resistência ou tolerância aos metabólitos secundários que atuam como aleloquímicos é mais ou menos específica, existindo espécies mais sensíveis que outras, como por exemplo, Lactuca sativa (alface) e Lycopersicum esculentun Mill. (tomate), por isso muito utilizadas em biotestes de laboratório (FERREIRA \& ÁQUILA, 2000).

Vários estudos de alelopatia têm sido conduzidos visando o controle de plantas daninhas. Entre eles está o Eucalipto, introduzido da Austrália, mas muito cultivado no Brasil, que tem várias espécies consideradas alelopáticas, pelo menos em potencial (FERREIRA \& ÁQUILA, 2000). Souto et al. (1994) verificaram que restos de Pinus radiata D. Don e Eucalyptus globulus Labill, inibiam o crescimento e desenvolvimento de alface e o efeito alelopático era devido principalmente a compostos fenólicos. Balbinot-Junior (2004) conseguiu suprimir a emergência e o crescimento de plantas de picão-preto através da aplicação de extrato aquoso de Mucuna spp. como herbicida de pré-emergencia em vasos. Extrato de Brachiaria plantaginea inibiu a germinação e provocou a redução do sistema radicular de Commelina bengalensis sob condições de laboratório (VOLL et al., 2004).

Realizou-se este trabalho com o objetivo de avaliar o efeito de extratos etanólicos de Eucalyptus citriodora Hook. e Pinus elliottii L. sobre a germinação e crescimento inicial de picão preto (Bidens pilosa) e alface (Lactuca sativa).

\section{MATERIAL E MÉTODOS}

As folhas das espécies de Eucalyptus citriodora e Pinus elliottii foram coletadas de plantas do Campus da Universidade Estadual de Londrina (UEL) - PR durante o período da manhã. Em seguida, estas folhas foram secas em estufa de circulação forçada de ar a $40^{\circ} \mathrm{C}$, e posteriormente trituradas.

Os materiais secos e moídos foram submetidos a três extrações sucessivas com etanol, a temperatura ambiente a intervalos de dois dias entre cada extração. Foi utilizado $100 \mathrm{~g}$ de massa seca de $E$. citriodora para 2,0 L de etanol p.a e $44 \mathrm{~g}$ de massa seca de $P$. elliottii para $0,75 \mathrm{~L}$ de etanol p.a para extração. Após cada extração, os materiais foram filtrados e encaminhados para evaporadores rotativos a vácuo à temperatura de $55^{\circ} \mathrm{C}$ para a total eliminação do etanol.

Os testes de germinação e crescimento foram realizados no laboratório de fitotecnia, Centro de Ciências Agrárias da Universidade Estadual de Londrina em outubro de 2005. Utilizou-se sementes de alface (Lactuca sativa L. cv. "Grand Rapids") e de picão-preto (Bidens pilosa) coletados no campus da UEL em outubro de 2005.

Os ensaios de germinação foram realizados em câmara de germinação do tipo BOD com fotoperíodo 10/14 horas de luz/escuro e temperaturas alternadas de $30^{\circ} \mathrm{C} /$ $20^{\circ} \mathrm{C}$ dia/noite para o picão-preto (ADEGAS et al., 2003) e temperatura constante de $20^{\circ} \mathrm{C}$ para a alface (BRASIL, 1992.). Os testes foram realizados em placas de Petri de 9,0 $\mathrm{cm}$ de diâmetro, revestidas com duas folhas de papel filtro previamente autoclavadas a $120^{\circ} \mathrm{C}$ por 30 minutos. Em cada placa foi adicionado $3,0 \mathrm{~mL}$ de cada extrato a ser testado nas concentrações de 0,$25 ; 0,50 ; 1,0$ e $2,0 \%$ obtidos a partir de $2,0 \mathrm{~g}$ de extrato bruto diluído em $50 \mathrm{~mL}$ de solução de Tween 20 a 4,0 \%, e para o controle $(0,0 \%)$ utilizou-se a solução de Tween 20 a $0,08 \%$. Foram semeadas 30 sementes por placa, previamente desinfestadas com hipoclorito de sódio a 2,5\% por dois minutos e lavadas com água autoclavada para o ensaio com o picão-preto, e as sementes de alface foram tratadas com o fungicida Captan na dosagem de $20 \mathrm{~g} \mathrm{~kg}^{-1}$. Os tratamentos foram dispostos em delineamento inteiramente casualizados com quatro repetições. A taxa de germinação foi verificada a cada 24 horas durante sete dias possibilitando a avaliação da velocidade de germinação. Foram consideradas germinadas as sementes que apresentaram $2 \mathrm{~mm}$ de protusão radicular (BRASIL, 1992).

A determinação do índice de velocidade de germinação (IVG) das sementes foi realizada conforme Maguire (1962), por meio de contagens diárias do número de sementes germinadas. 
As análises de crescimento das plântulas foram realizadas com sementes pré-germinadas de picão-preto por 72 horas, e de alface por 48 horas nas mesmas condições dos testes de germinação. Oito plântulas de picão-preto e dez de alface foram distribuídas em placas de Petri de 9,0 cm de diâmetro, revestidas com duas folhas de papel filtro, previamente umedecidas com os extratos de E. citriodora e de P. elliottii com quatro repetições. A metodologia e os tratamentos foram os mesmos utilizados nos ensaios de germinação. Após sete dias de crescimento, o comprimento da radícula de cada plântula foi medido com o auxílio de um paquímetro.

Os ensaios foram realizados em câmara de fluxo laminar para evitar possíveis contaminações.

Os dados obtidos foram submetidos à análise de variância e a comparação entre as médias foi realizada pelo teste de Tukey a $5 \%$

\section{RESULTADOS E DISCUSSÃO}

No experimento com o picão-preto, a germinação e o índice de velocidade de germinação (IVG) não foram afetados pelo extrato etanólico de Pinus elliottii nas cinco concentrações testadas. O extrato etanólico de Eucalyptus citriodora reduziu significativamente a germinação das sementes até o terceiro dia de avaliação nas concentrações de $1,0 \%$ e $2,0 \%$ em relação ao controle $(0,0 \%)$, porém, não foi possível observar diferença significativa entre os tratamentos na avaliação final da germinação (sétimo dia) (Tabela 1). Entretanto, Cruz et al. (2000) observaram inibição total da germinação de sementes de picão-preto (B. pilosa) e cerca de $60 \%$ de sementes de guanxuma (Sida rhombifolia L.) pelo extrato bruto aquoso de Eucalyptus citriodora a $30 \%$ de concentração peso/volume. Assim, observa-se que o potencial alelopático das plantas difere de acordo com a espécie vegetal.

Quanto à velocidade de germinação das sementes de picão-preto, pode-se observar que o extrato de $E$. citriodora causou atraso significativo na germinação em todas as concentrações testadas quando comparadas com a testemunha (Tabela 1).

$\mathrm{O}$ efeito alelopático pode ocorrer não sobre a germinabilidade (percentual final de germinação no tempo), mas sobre a velocidade de germinação e provocar alterações na curva de distribuição da germinação, alongando a curva através do eixo do tempo (FERREIRA \& ÁQUILA, 2000) como pode ser observado nas Figuras 1 e 2. Os resultados estão de acordo com os obtidos por Teixeira et al. (2004), os quais verificaram inibição da germinação do picão-preto pelo extrato aquoso de Crotalaria juncea L. a $12 \%$ peso/volume e não redução da velocidade de germinação. Neste mesmo trabalho, o extrato aquoso de mucuna preta (Stilozobium aterrimum Piper \& Tracy) a $12 \%$ peso/volume não inibiu a porcentagem de germinação do picão, porém reduziu a velocidade de germinação.

TABELA 1 - Porcentagem de germinação com três e sete dias após a semeadura, índice de velocidade de germinação (IVG) e comprimento radicular (cm) de sementes de picão-preto (Bidens pilosa) sob efeito de extratos etanólicos de Pinus elliottii e Eucalyptus citriodora. Londrina, 2005.

\begin{tabular}{ccccc}
\hline Doses dos Extratos (\%) & $\begin{array}{c}\text { Germinação (\%) c/ } \\
\text { 3 dias }\end{array}$ & $\begin{array}{c}\text { Germinação (\%) c/ } \\
\mathbf{7 ~ d i a s ~}\end{array}$ & IVG & $\begin{array}{c}\text { Comprimento } \\
\text { Radicular (cm) }\end{array}$ \\
\hline Pinus elliottii & & & $11,2 \mathrm{a}$ & $1,9 \mathrm{a}$ \\
0,00 & $85,0 \mathrm{a}$ & $91,6 \mathrm{a}$ & $10,0 \mathrm{a}$ & $1,9 \mathrm{a}$ \\
0,25 & $75,8 \mathrm{a}$ & $95,0 \mathrm{a}$ & $9,3 \mathrm{a}$ & $2,1 \mathrm{a}$ \\
0,50 & $75,8 \mathrm{a}$ & $92,5 \mathrm{a}$ & $9,5 \mathrm{a}$ & $1,9 \mathrm{a}$ \\
1,00 & $73,3 \mathrm{a}$ & $90,8 \mathrm{a}$ & $9,5 \mathrm{a}$ & 14,30 \\
2,00 & $76,6 \mathrm{a}$ & $91,6 \mathrm{a}$ & 14,32 & $1,9 \mathrm{a}$ \\
CV $\%$ & 17,10 & 6,32 & & $2,2 \mathrm{a}$ \\
Eucalyptus citriodora & & & $11,6 \mathrm{a}$ & $2,1 \mathrm{a}$ \\
0,00 & $85,8 \mathrm{a}$ & $94,2 \mathrm{a}$ & $9,2 \mathrm{~b}$ & $2,2 \mathrm{a}$ \\
0,50 & $63,3 \mathrm{ab}$ & $91,7 \mathrm{a}$ & $7,3 \mathrm{~b}$ & $1,8 \mathrm{a}$ \\
1,00 & $51,7 \mathrm{ab}$ & $81,7 \mathrm{a}$ & $7,8 \mathrm{~b}$ & 17,13 \\
CV $\%$ & $35,8 \mathrm{~b}$ & $83,3 \mathrm{a}$ & 21,49 & $\mathrm{a}$ \\
\hline
\end{tabular}

Médias seguidas da mesma letra, nas colunas, não diferem entre si pelo teste de Tukey, ao nível de $5 \%$ de significância. 
(a)

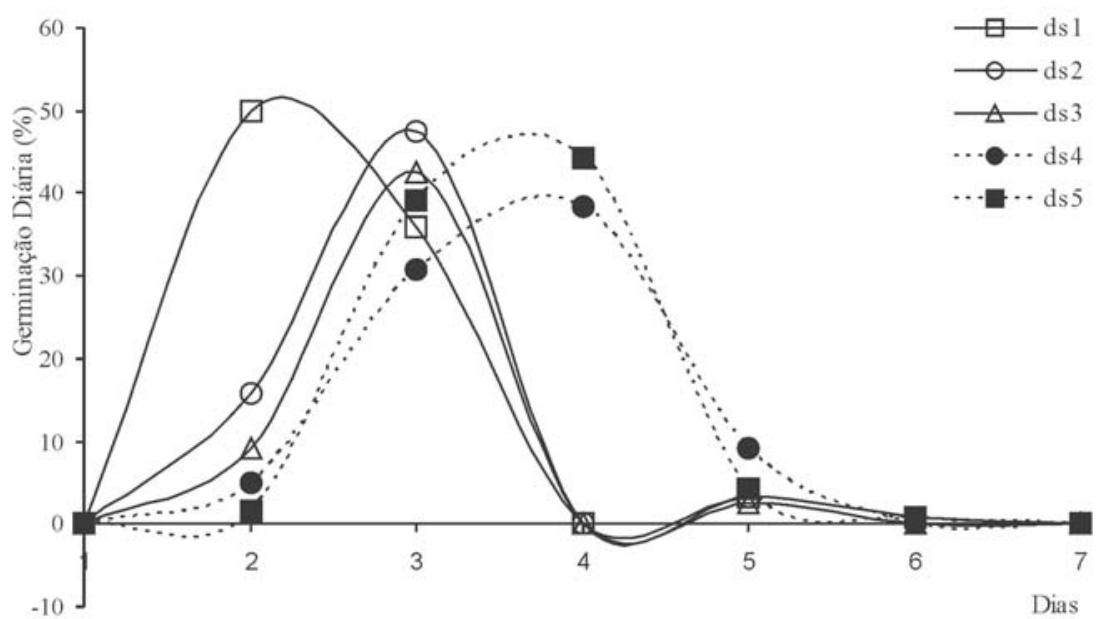

(b)

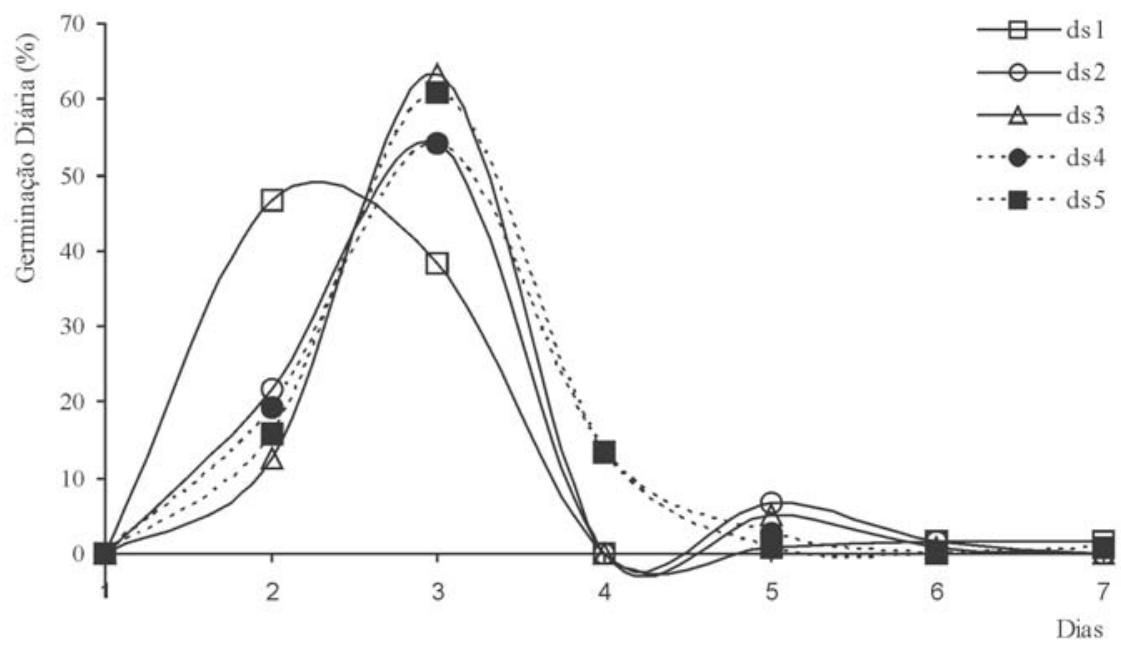

FIGURA 1 - Germinação diária, não acumulativa, de sementes de picão-preto (Bidens pilosa) sob efeito dos extratos etanólicos de Eucalyptus citriodora (a) e Pinus elliottii (b).

Em relação à variável comprimento de radícula das plântulas de picão-preto, tanto para o extrato de $P$. elliottii quanto para o de E. citriodora não foi possível observar diferença significativa entre os tratamentos.

No experimento com a alface, os extratos não reduziram significativamente a germinação nem afetaram o comprimento da radícula em nenhuma das concentrações testadas (Tabela 2).

Quanto ao IVG das sementes de alface, a aplicação do extrato de E. citriodora na concentração de 2,00\% promoveu redução significativa da velocidade de germinação quando comparada com os demais tratamentos. Na presença de $P$. elliottii, não houve atraso na germinação das sementes de alface em nenhuma das concentrações testadas.

Os resultados encontrados mostraram que o extrato etanólico de $P$. elliottii não apresentou efeito alelopático para as variáveis analisadas tanto para o picão-preto quanto para o alface. Estes resultados diferem dos encontrados por Schumann et al. (1995) que em experimentos realizados com extratos aquosos e restos culturais de Pinus patula Schiede \& Deppe e Eucalyptus grandis W. Hill ex Maiden 
(a)

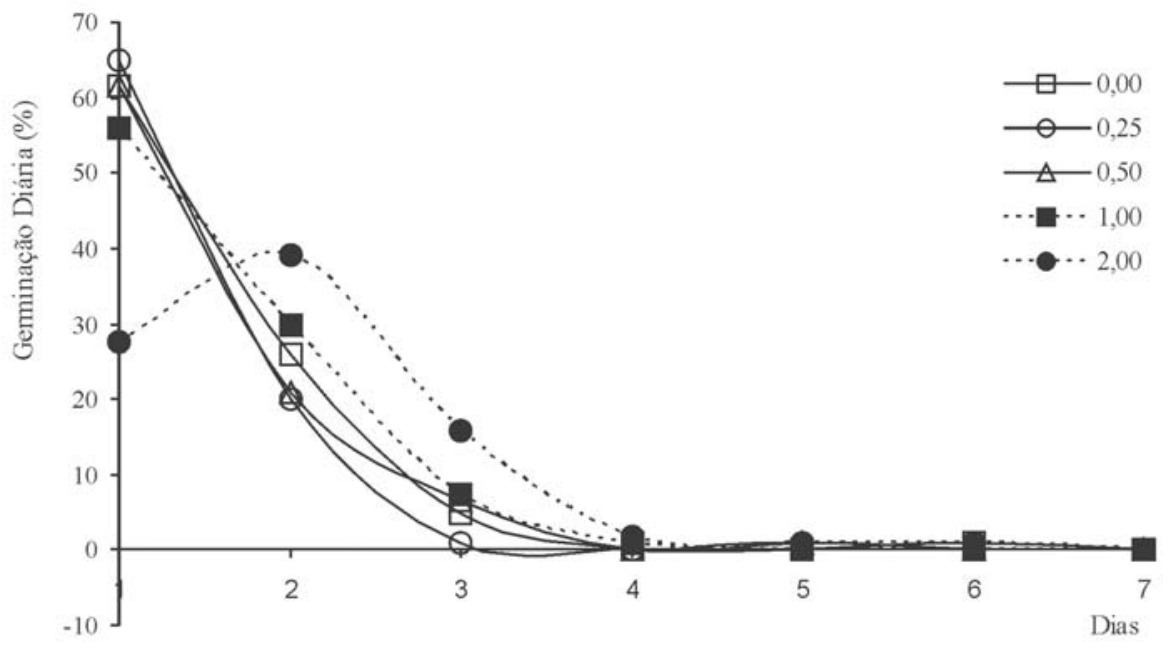

(b)

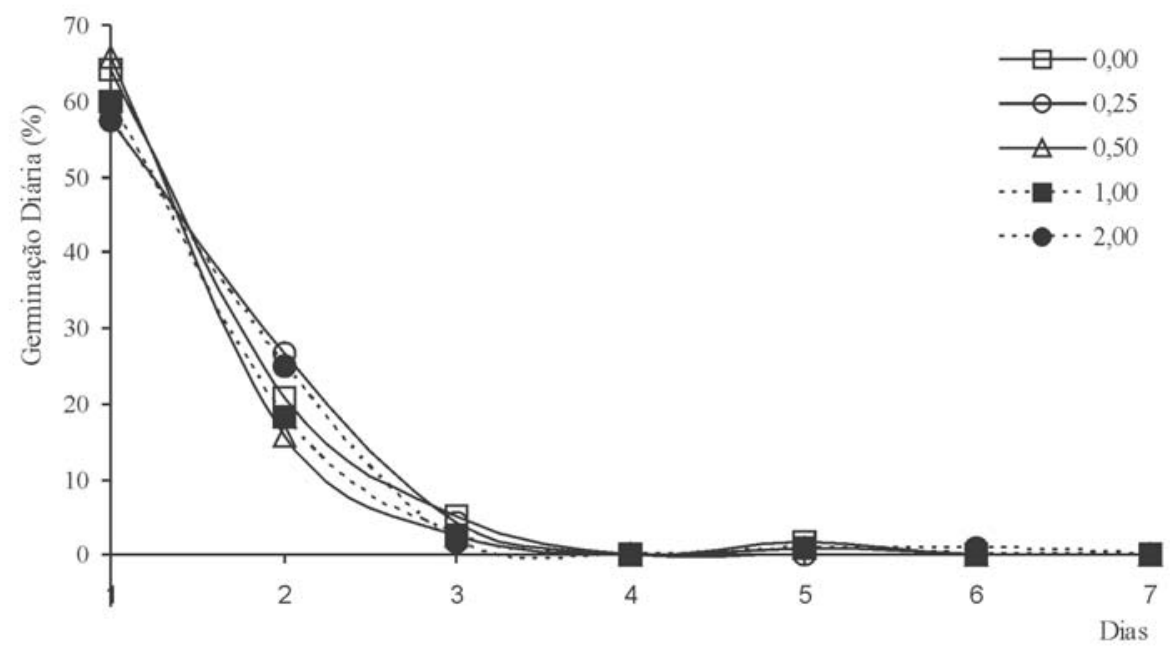

FIGURA 2 - Germinação diária, não acumulativa, de sementes de alface (Lactuca sativa) sob efeito dos extratos etanólicos de Eucalyptus citriodora (a) e Pinus elliottii (b).

suprimiram a germinação de plantas daninhas, com Pinus patula apresentando resultados superiores aos do Eucalyptus grandis.

Este fato pode ser atribuído ao tipo de extrato e/ou as concentrações utilizadas nos ensaios, pois estudos realizados por Cruz et al. (2000) constataram que a forma de preparo, o método de aplicação e a concentração dos produtos são fatores decisivos na obtenção de resultados, pois princípios ativos vegetais são instáveis e não se distribuem de forma homogênea na planta. 
TABELA 2 - Porcentagem de germinação com três e sete dias após a semeadura, índice de velocidade de germinação (IVG) e comprimento radicular (cm) de sementes de alface (Lactuca sativa) sob efeito de extratos etanólicos de Pinus elliottii e Eucalyptus citriodora. Londrina, 2005.

\begin{tabular}{ccccc}
\hline Doses dos Extratos (\%) & $\begin{array}{c}\text { Germinação (\%) c/ } \\
\text { 3 dias }\end{array}$ & $\begin{array}{c}\text { Germinação (\%) c/ } \\
\text { 7 dias }\end{array}$ & IVG & $\begin{array}{c}\text { Comprimento } \\
\text { Radicular (cm) }\end{array}$ \\
\hline Pinus elliottii & & & & \\
0,00 & $90,0 \mathrm{a}$ & $94,2 \mathrm{a}$ & $23,0 \mathrm{a}$ & $3,2 \mathrm{a}$ \\
0,25 & $88,3 \mathrm{a}$ & $89,2 \mathrm{a}$ & $21,8 \mathrm{a}$ & $3,4 \mathrm{a}$ \\
0,50 & $84,2 \mathrm{a}$ & $85,8 \mathrm{a}$ & $22,5 \mathrm{a}$ & $3,4 \mathrm{a}$ \\
1,00 & $80,8 \mathrm{a}$ & $81,7 \mathrm{a}$ & $21,1 \mathrm{a}$ & $3,4 \mathrm{a}$ \\
2,00 & $84,2 \mathrm{a}$ & $85,8 \mathrm{a}$ & $21,2 \mathrm{a}$ & $3,0 \mathrm{a}$ \\
CV \% & 9,57 & 9,80 & 12,53 & 11,74 \\
Eucalyptus citriodora & & & & \\
0,00 & $92,5 \mathrm{a}$ & $93,3 \mathrm{a}$ & $22,9 \mathrm{a}$ & $3,2 \mathrm{a}$ \\
0,25 & $85,8 \mathrm{a}$ & $86,7 \mathrm{a}$ & $22,6 \mathrm{a}$ & $3,1 \mathrm{a}$ \\
0,50 & $89,2 \mathrm{a}$ & $90,0 \mathrm{a}$ & $22,3 \mathrm{a}$ & $3,3 \mathrm{a}$ \\
1,00 & $93,3 \mathrm{a}$ & $94,2 \mathrm{a}$ & $22,1 \mathrm{a}$ & $3,5 \mathrm{a}$ \\
2,00 & $82,5 \mathrm{a}$ & $85,8 \mathrm{a}$ & $15,9 \mathrm{~b}$ & $2,9 \mathrm{a}$ \\
CV \% & 8,03 & 7,11 & 16,38 & 10,61 \\
\hline
\end{tabular}

Médias seguidas da mesma letra, nas colunas, não diferem entre si pelo teste de Tukey, ao nível de $5 \%$ de significância.

\section{CONCLUSÕES}

O extrato etanólico de Pinus elliottii não demonstrou efeito alelopático sobre o picão-preto e alface.

O extrato etanólico de Eucalyptus citriodora reduziu a velocidade de germinação do picão-preto.

O picão-preto mostrou-se mais sensível que a alface sob o efeito do extrato etanólico de Eucalyptus citriodora.

\section{REFERÊNCIAS BIBLIOGRÁFICAS}

ADEGAS, F. S.; VOLL, E.; PRETE, C. E. C. Embebição e germinação de sementes de picão-preto (Bidens pilosa). Planta Daninha, Viçosa, v. 21, n. 1, p. 21-25, 2003.

BALBINOT-JUNIOR, A. A. Manejo das plantas daninhas pela alelopatia. Agropecuária Catarinense, Florianópolis, v. 17, n. 1, p. 61-64, 2004.

BIANCHI, M. A. Programa de difusão do manejo integrado de plantas daninhas em soja no Rio Grande do Sul: 1994/ 95. Cruz Alta: FUNDACEP FECOTRIGO, 1995. 31 p.

BRASIL. Ministério da Agricultura e Reforma Agrária. Regras para análise de sementes. Brasília, DF: SNDA/ DNDV/CLAV, 1992. 365 p.
CRUZ, S. E. M.; NOZAKI, M. H.; BATISTA, M. A. Plantas medicinais. Biotecnologia Ciência e Desenvolvimento, Brasília, n. 15, p. 28-34, 2000.

FAVERO, C.; JUCKSCH, I.; ALVARENGA, R. C.; COSTA, L. M. da. Modificações na população de plantas espontâneas na presença de adubos verdes. Pesquisa Agropecuária Brasileira, Brasília, v. 36, n. 11, p. 1355$1362,2001$.

FERREIRA, A. G.; AQUILA, M. E. A. Alelopatia: uma área emergente da ecofisiologia. Revista Brasileira de Fisiologia Vegetal, Brasília, v. 12, p. 175-204, 2000. Edição especial.

KISSMANN, G. K. Plantas daninhas e nocivas. 2. ed. São Bernardo do Campo: BASF Brasileira, 1997. tomo 1, 825 p.

MAGUIRE, J. D. Speed of germination-aid in selection evaluation for seedling emergence and vigour. Crop Science, Madison, v. 2, p. 176-177, 1962.

MEDEIROS, A. R. M. Alelopatia: importância e suas aplicações. Horti Sul, Pelotas, v. 1, n. 3, p. 27-32, 1990. 
RICE, E. L.Allelopathy. 2. ed. New York: Academic, 1984. 422 p.

SCHUMANN, A. W.; LITTLE, K. M.; ECCLES. Suppression of seed germination and early seedling growth by plantation harvest residues. South African Journal of plant and Soil, Pretoria, v. 12, n. 4, p. 170-172, 1995.

SOUTO, X. C.; GONZALEZ, L.; REIGOSA, M. J. Comparative analysis of allelopathic effects produced by four foresty species during decomposition process in their soils in Galicia (NW. Spain). Journal of Chemical Ecology, New York, v. 20, n. 11, p. 3005-3015, 1994.
TEIXEIRA, C. M.; ARAUJO, J. B. S.; CARVALHO, G. J. de. Potencial alelopático de plantas de cobertura no controle de picão-preto (Bidens pilosa L.). Ciência Agrotecnologia, Lavras, v. 28, n. 3, p. 691-695, 2004.

VOLL, E.; FRANCHINI, J. C.; CRUZ, R. T.; GAZZIERO, D. L. P.; BRIGHENTI, A. M.; ADEGAS, F. $\mathrm{S}$. Chemical interations of Brachiaria plantaginea with Commelina bengalensis and Acanthospermun hispidum in soybean cropping systems. Journal of Chemical Ecology, New York, v. 30, n. 7, p. 1467-1475, 2004. 